\title{
Making Sense of Recent Acute Stroke Trial Results
}

\author{
Nawaf Yassi $\cdot$ Patrik Michel $\cdot$ Mark Parsons
}

Published online: 13 March 2014

(c) Springer Science+Business Media New York 2014

\begin{abstract}
The acute stroke treatment landscape is rapidly evolving. A number of recent stroke trial results have provided promising insights into new treatment strategies, while other trials have yielded neutral or negative results. This article is a review of recent acute trials in both ischemic stroke and intracerebral hemorrhage, with a focus on trial design, analysis of methodology, relevance of the results to the clinic and lessons learned for future stroke trials. In particular, we will highlight current controversies in the field pertaining to the optimal selection of stroke trial endpoints, the use of advanced imaging to select treatment candidates and the burgeoning field of endovascular intervention for stroke.
\end{abstract}

Keywords Stroke - Thrombolytic Therapy · Intracerebral Hemorrhage - Clinical Trials . Endovascular treatment $\cdot$ Multimodal neuroimaging

This article is part of the Topical Collection on Advances in NeuroImaging.

\section{N. Yassi $(\bowtie)$}

Departments of Medicine and Neurology, Melbourne Brain

Centre @ The Royal Melbourne Hospital, University of

Melbourne, Parkville, Melbourne, VIC, Australia

e-mail: nawaf.yassi@mh.org.au

P. Michel

Stroke Center, Neurology Service, Centre Hospitalier

Universitaire Vaudois and University of Lausanne, Lausanne,

Switzerland

M. Parsons

Department of Neurology and Hunter Medical Research Institute, John Hunter Hospital, University of Newcastle, Newcastle, NSW, Australia

\section{Background}

Stroke is part of a growing global pandemic of non-communicable diseases. According to the latest iteration of the Global Burden of Disease Study, stroke was the second most common cause of mortality worldwide in 2010, causing $\sim 5.8$ million deaths [1]. In addition, stroke was the third most common cause of disability [measured in disability-adjusted life years (DALYs)] when considering all age groups and all regions of the world [2]. Recent years have seen a vast body of both pre-clinical and clinical research aimed at improving stroke care as well as research targeted at primary and secondary prevention, public health and global institution of evidence-based stroke practices. We present herein a review of recent acute stroke treatment trials and a discussion of how these trials shape the future research landscape. We also discuss important issues pertaining to the interpretation of the results of these trials.

\section{Endovascular Stroke Trials}

The advent and widespread utilization of cerebrovascular interventional techniques in stroke, particularly the use of modern "stentrievers," has been widely heralded as the new frontier in ischemic stroke. However, level-1 evidence of efficacy compared to the standard of care [intravenous recombinant tissue plasminogen activator (rtPA)] is still lacking. Three recently published trials have attempted to provide this evidence, but did not prove superiority over intravenous rtPA and have been the subject of heated discussion. Table 1 provides a side-by-side overview of the methodology and results of these trials.

The Third Interventional Management of Stroke (IMS3) trial began recruitment in 2006 and was terminated early 
Table 1 Side-by-side summary of recent interventional stroke trials

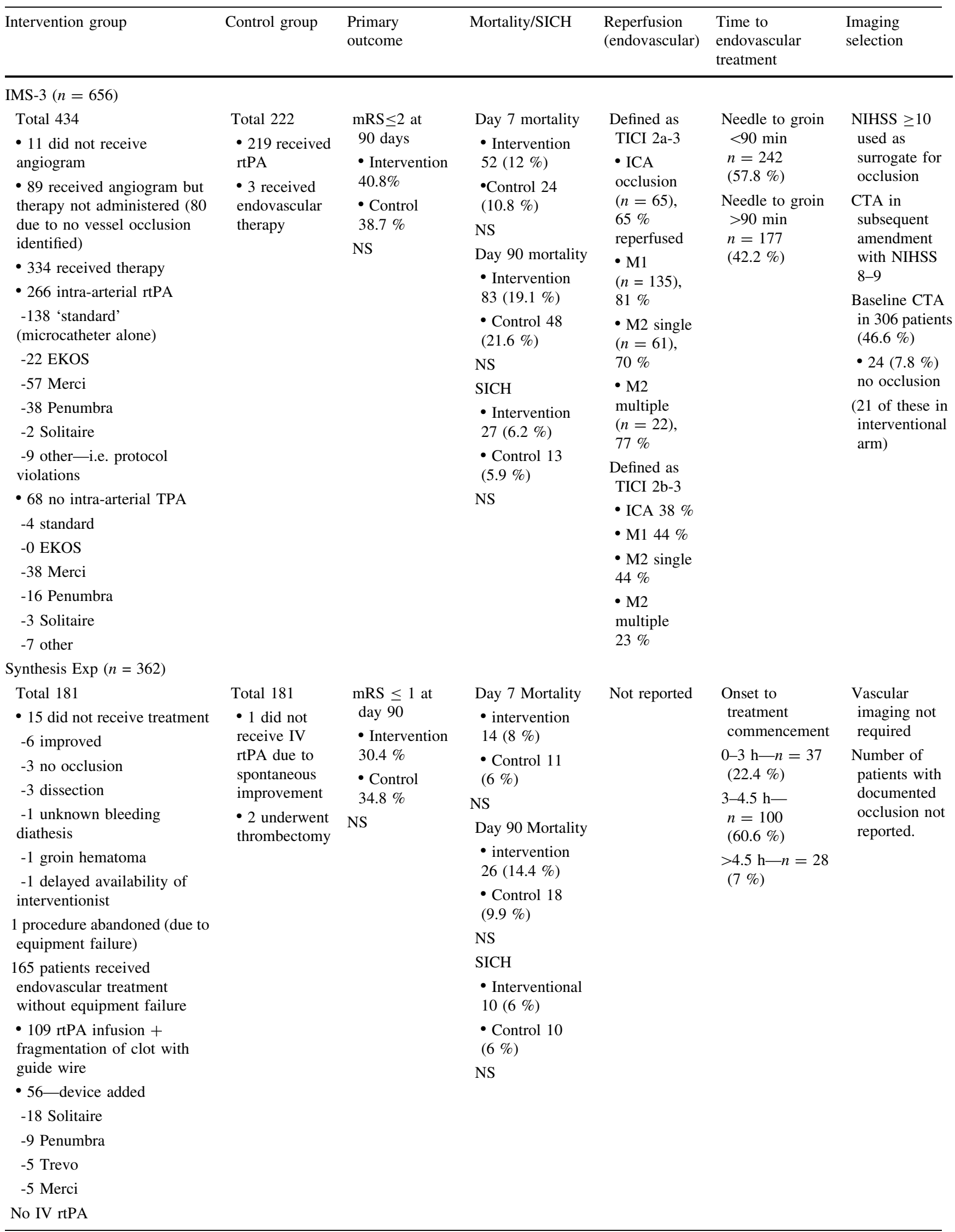


Table 1 Side-by-side summary of recent interventional stroke trials

\begin{tabular}{|c|c|c|c|c|c|c|}
\hline Intervention group & Control group & $\begin{array}{l}\text { Primary } \\
\text { outcome }\end{array}$ & Mortality/SICH & $\begin{array}{l}\text { Reperfusion } \\
\text { (endovascular) }\end{array}$ & $\begin{array}{l}\text { Time to } \\
\text { endovascular } \\
\text { treatment }\end{array}$ & Imaging selection \\
\hline $\begin{array}{l}\text { MR-rescue }(\mathrm{n}=118) \\
\text { Total } 64 \\
\text { - Interventional- } \\
\text { penumbral } n=34 \\
-16(47 \%) \text { had IV } \\
\text { rtPA } \\
\text { • Interventional-non- } \\
\text { penumbral } n=30 \\
-12(40 \%) \text { had IV } \\
\text { rtPA } \\
37 \text { Merci } \\
14 \text { Penumbra } \\
10 \text { Both } \\
3 \text { Neither (recanalized } \\
\text { prior to angiogram) } \\
8 \text { had adjunctive IA } \\
\text { rtPA [mean dose } \\
5.1 \text { m (range } \\
2-12 \text { mg)] }\end{array}$ & $\begin{array}{l}\text { Total } 54 \\
\text { - Control- } \\
\text { penumbral } \\
n=34 \\
-9(26 \%) \\
\text { had IV rtPA } \\
\text { - Control- } \\
\text { non- } \\
\text { penumbral } \\
n=20 \\
-7(35 \%) \\
\text { had IV rtPA }\end{array}$ & 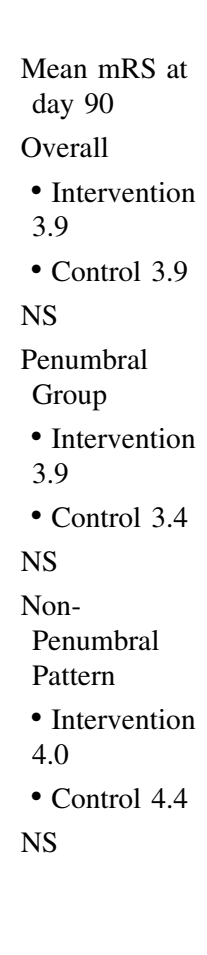 & $\begin{array}{l}\text { Day } 90 \text { Mortality } \\
\text { Interventional- } \\
\text { penumbral } 6 \\
(18 \%) \\
\text { Control-penumbral } \\
7(21 \%) \\
\text { Interventional-non- } \\
\text { penumbral } 6 \\
(20 \%) \\
\text { Control-non- } \\
\text { penumbral } 6 \\
(30 \%) \\
\text { NS } \\
\text { SICH } \\
\text { Interventional- } \\
\text { penumbral } 3 \text { (9 \%) } \\
\text { Control-penumbral } \\
2 \text { (6 \%) } \\
\text { Interventional-non- } \\
\text { penumbral } 0 \\
\text { Control-non- } \\
\text { penumbral } 0 \\
\text { NS }\end{array}$ & $\begin{array}{l}\text { Defined as } \\
\text { TICI } 2 \mathrm{a}-3 \text { at } \\
\text { end of } \\
\text { procedure } \\
\text { Penumbral } 20 \\
(59 \%) \\
\text { Non- } \\
\text { penumbral } 23 \\
(77 \%) \\
\text { Defined as } \\
\text { TICI } 2 \mathrm{~b}-3 \text { at } \\
\text { end of } \\
\text { procedure } \\
\text { Penumbral } 8 \\
(24 \%) \\
\text { Non- } \\
\text { penumbral } 8 \\
(27 \%) \\
\text { Note primary } \\
\text { assessment of } \\
\text { reperfusion in } \\
\text { trial was at } \\
\text { day } 7\end{array}$ & $\begin{array}{l}\text { Onset to } \\
\text { enrolment } \\
\text { • Mean } \\
5.5 \mathrm{~h} \text { (SD } \\
1.4 \mathrm{~h} \text { ) } \\
\text { Onset to } \\
\text { groin } \\
\text { puncture } \\
\text { - Mean } 6 \mathrm{~h} \\
21 \text { min (SD } \\
1 \text { h } 14 \text { min) } \\
\text { Imaging to } \\
\text { groin } \\
\text { puncture } \\
\text { - Mean } 2 \mathrm{~h} \\
4 \text { min (SD } \\
56 \text { min) }\end{array}$ & $\begin{array}{l}\text { Multimodal MRI } \\
(80 \%) \text { or CT } \\
\text { Penumbral pattern } \\
\text { defined based on } \\
\text { voxel by voxel } \\
\text { analysis } \\
\text { incorporating } \\
\text { multiple } \\
\text { parameters } \\
\text { (including NIHSS } \\
\text { in CTP) }\end{array}$ \\
\hline
\end{tabular}

EKOS EKOS MicroSonic ${ }^{\circledR}$ SV Infusion System; Merci Merci ${ }^{\circledR}$ Retriever; Penumbra Penumbra System ${ }^{\text {TM}}$; Solitaire Solitaire Stent Revascularization Device; Trevo Trevo Retriever; NS not significant; SICH symptomatic intracranial hemorrhage; SD standard deviation; TICI thrombolysis in cerebral infarction score; $I C A$ internal carotid artery; $M 1$ middle cerebral artery M1 segment; $M 2$ middle cerebral artery M2 segment

Table 2 [26] - Thrombolysis in cerebral infarction (TICI) score

\begin{tabular}{ll}
$\begin{array}{l}\text { TICI } \\
\text { score }\end{array}$ & \\
\hline 0 & $\begin{array}{l}\text { No reperfusion } \\
\text { Perfusion past the initial obstruction but limited distal } \\
\text { branch filling with little or slow distal perfusion }\end{array}$ \\
$2 \mathrm{a}$ & $\begin{array}{c}\text { Perfusion of }<50 \% \text { of the vascular distribution of the } \\
\text { occluded artery }\end{array}$ \\
$2 \mathrm{~b}$ & $\begin{array}{c}\text { Perfusion of } \geq 50 \% \text { of the vascular distribution of the } \\
\text { occluded artery }\end{array}$ \\
3 & Full perfusion with filling of all distal branches
\end{tabular}

because of futility on the primary end point [proportion of patients with a modified Rankin score (mRS) $\leq 2$, which equates to no or mild disability, at 90 days] after recruiting 656 patients [3]. The trial was a phase-3 study with a prospective, 2:1 (interventional to standard care) randomized open-label, blinded endpoint (PROBE) design, with an aim of comparing a combined intravenous-intra-arterial approach to intravenous rtPA alone. It recruited patients aged 18-82 with a National Institute of Health Stroke
Score (NIHSS) $\geq 10$ who received intravenous rtPA within $3 \mathrm{~h}$ of stroke onset. The initial specified dose of intravenous rtPA was two-thirds of the standard dose, with the remaining one-third given intra-arterially in the interventional group or intravenously in the control group. This was subsequently amended to allow full-dose intravenous rtPA to be given in the interventional group. An amendment after 284 recruitments also allowed for NIHSS 8-9 with an occlusion seen in the middle cerebral artery M1 segment, internal carotid artery (ICA) or basilar artery on computed tomography angiography (CTA). The rapid evolution of the interventional field became apparent during the trial, whereby approval of new devices, more routine use of CTA and use of full-dose intravenous rtPA followed by intra-arterial therapy became commonplace during the latter part of the 6-year enrollment period.

The Local Versus Systemic Thrombolysis for Acute Ischemic Stroke (SYNTHESIS) Expansion trial also had a PROBE design and recruited patients between the age of 18-80 years within $4.5 \mathrm{~h}$ of symptom onset [4]. In contrast to IMS-3, patients in the endovascular treatment arm did not receive any intravenous rtPA. In the interventional 
group, either intra-arterial infusion of rtPA, or mechanical thrombectomy or a combination were permitted, and where no vessel occlusion was identified on angiography but the patient had ongoing deficits, rtPA was injected into the presumed culprit vascular territory at a dose determined by the operator. The primary endpoint was $m R S \leq 1$ at 90 days indicating no ongoing stroke symptoms or mild symptoms with no disability. This trial recruited a total of 362 patients from 2008 to 2012, randomized 1:1. There were no significant differences between the groups on the primary efficacy endpoint.

The Mechanical Retrieval and Recanalization of Stroke Clots Using Embolectomy (MR-RESCUE) trial was a phase $2 b$ PROBE design study that sought to incorporate advanced imaging selection to determine whether selecting patients based on a 'favorable penumbral imaging pattern' predicted better response to clot retrieval [5]. This trial ran from 2004 to 2011 and recruited 118 patients aged 18-85 within $8 \mathrm{~h}$ of symptom onset. Randomization was stratified based on penumbral imaging with computed tomography perfusion (CTP) or magnetic resonance perfusion-weighted imaging (PWI). The trial also included patients who received intravenous rtPA as standard care without successful recanalization. The primary outcome measure was 90-day mRS, and this was tested by determining whether pretreatment imaging had a significant interaction with treatment assignment as a determinant of mRS shift across all seven levels ( 0 , being asymptomatic, to 6 , being dead), and this analysis did not show a significant interaction.

The overall negative result of these three trials elicits several comments. First, the studies show the importance of prospective randomized trials and provide a caveat that endovascular treatment is not an easy road to success without limitations and pathophysiological constraints.

Second, the evolving landscape of device technology, shifting clinical practice and the international variability in regulatory procedures have led to the interventional arms in these trials being highly heterogeneous and consisting of a variable mix of intra-arterial infusion of rtPA, mechanical disruption of thrombus using guidewires, and more recently a number of devices with variable evidence of recanalization efficacy (Table 1). Case series and randomized trials have shown improving recanalization rates up to $90 \%$ leading to better clinical outcome when comparing modern generation stent retrievers [such as SOLITAIRE FR (Covidien, Mansfield, MA, USA)] with first generation devices [such as the MERCI device (Concentric Medical, Mountain View, CA, USA)] [6, 7]. Increasing operator experience, higher treatment volumes and improved intrahospital treatment pathways may also lead to further improvements in the efficiency of endovascular treatments.
One of the strongest messages to come from the three recent interventional trials is the importance of the 'time is brain' concept. Reduction in treatment delays is known to be critically important in the implementation of intravenous rtPA therapy $[8,9]$ and is likely to be at least as important in intra-arterial therapy. In essence, as time to treatment increases, the risk-benefit equation becomes more skewed away from benefit and potentially more toward risk. A review of the times to treatment in the three trials suggests that systems and procedures must be implemented in order to ensure rapid triage, assessment and treatment. In particular, intrahospital delays from imaging to randomization to reperfusion should be minimized. In IMS-3, $42.2 \%$ of patients had a time from commencement of intravenous rtPA to groin puncture of greater than $90 \mathrm{~min}$ [3]. In addition, there was a significant correlation between earlier recanalization and improved outcome [10], as was recently also shown in a pooled analysis of seven endovascular trials [11]. In SYNTHESIS, the median time from stroke onset to the start of treatment was $3.75 \mathrm{~h}$ for endovascular therapy and $2.75 \mathrm{~h}$ for intravenous $\operatorname{rtPA}(p<0.001)$, an additional delay of $1 \mathrm{~h}$, during which patients in the endovascular group did not receive concurrent intravenous rtPA [4]. The fact that both treatment groups had similar outcomes despite this delay was reassuring as it provides evidence that endovascular recanalization is at least as efficient as intravenous thrombolysis, offering an effective alternative treatment in patients with contraindications to intravenous rtPA such as a systemic bleeding tendency. In MR-RESCUE, the mean delay from imaging to groin puncture was $2.4 \mathrm{~h}$ [5].

The optimal method for selecting patients for enrollment in acute stroke trials has also been hotly debated based on the results of the aforementioned trials. Appropriate selection aims to identify patients in whom an intervention (in the case of stroke: revascularization) is likely to yield benefit (improved clinical outcome), while minimizing the risk of adverse events [intracerebral hemorrhage (ICH) or procedural complications]. Both IMS-3 and SYNTHESIS allowed for the use of stroke severity (NIHSS) as a surrogate marker for vessel occlusion, without the specific need for vascular imaging to demonstrate an occlusion. Although a threshold NIHSS $\geq 10$ has been shown to reliably predict vessel occlusion [12, 13], the lack of documentation of vessel occlusion prior to treatment is likely to add to negative trial results. In IMS-3, for example, 80 $(18.4 \%)$ of the 434 patients in the interventional arm did not have an arterial occlusion on angiography [3]. Such patients would potentially be exposed to the risks of an intervention but not the potential benefits of recanalization.

Reperfusion of infarcted tissue is unlikely to be of benefit and indeed is likely to be associated with harm. 
Reperfusion of areas of severe tissue hypoperfusion as defined by PWI or CTP has been associated with hemorrhagic transformation $[14,15]$ and with poor clinical outcome [16]. On the other hand, reperfusion may be of most benefit in patients with a large area of hypoperfused but potentially viable tissue (the "penumbral profile" or "target mismatch") [17, 18, 19॰]. While MR-RESCUE used imaging to classify patients with a penumbral profile, the methods used were different from standard mismatchbased methods and involved voxel-wise analysis of multiple perfusion parameters as well as NIHSS in the case of CTP [20]. It is also notable that initial post-processing of the imaging at the local center in MR-RESCUE failed in $\sim 42 \%$ of cases and that final analysis of the imaging at the core site resulted in a changed allocation in $8.5 \%$ of cases [5]. The alternative mismatch-based hypothesis for selecting patients with penumbral characteristics may be more practical and reproducible, particularly using CTP, which is more widely available and may reduce delays to treatment [21-24]. In addition, MR-RESCUE included patients in the 'penumbral' group with exceptionally large pre-treatment infarct cores (up to $90 \mathrm{ml}$, median $60 \mathrm{ml}$ ). A number of groups have shown that the likelihood of good outcome diminishes rapidly as the baseline infarct core increases $[18,25]$, again emphasizing the need to avoid inclusion of 'futile reperfusion' cases in future trials.

A common argument against the use of penumbral imaging for treatment selection has been that this leads to delays in treatment. Ironically, even though the delays described above in the recently reported trials occurred mostly post-imaging, this has led some interventionalists to promote patient selection based purely on non-contrast CT as more advanced imaging may 'waste' time. However, we suggest that further 'unselected' trials of acute reperfusion therapy are unlikely to advance the field. Future trials should emphasize the importance of rapid multimodal imaging assessment and treatment in order to minimize these delays.

Another issue raised in these trials was the definition of the optimal revascularization/reperfusion target. Both IMS3 and MR-RESCUE used the thrombolysis in the cerebral infarction (TICI) scale to measure the effectiveness of the interventional procedure (Table 2) [26]. These trials defined successful revascularization as achieving TICI-2a or better (SYNTHESIS has not reported on revascularization endpoints or rates). A secondary analysis in IMS-3 demonstrated a significant correlation between the odds of good clinical outcome and improved degrees of TICI revascularization [3]. Moreover, in MR-RESCUE, there was a significant association between reperfusion (defined as a reduction of more than $90 \%$ in the volume of the perfusion lesion) or revascularization (defined as TICI 2a or better), and better 90-day mRS [5]. This was the case despite the primary reperfusion parameter being at day 7 in this trial, which may include instances of delayed ( $>24 \mathrm{~h}$ ) and non-nutritional (futile) spontaneous reperfusion and thus may have diluted any benefits of effective early recanalization. In addition, there is now growing evidence that TICI-2a is a relatively poor predictor of good clinical outcome and that a revascularization target of TICI- $2 b$ or better should be the aim as this is more strongly associated with good outcome [27-29]. This endpoint was achieved in only a minority of patients in the recent trials (Table 1). Finally, recent data suggest that tissue reperfusion measured directly (i.e., with early post-treatment perfusion imaging and using modern post-processing) has the strongest association with good outcome (provided those with large pre-reperfusion infarct cores are excluded) [30, 31]. We would suggest that while a procedural target of TICI$2 \mathrm{~b}$ or higher should be the aim, perfusion imaging assessment of tissue reperfusion is the gold standard and should be used for assessing future acute reperfusion therapies.

While the negative result of MR RESCUE has been used as an argument against advanced imaging selection, these results contrast dramatically with the non-randomized second diffusion and perfusion imaging for understanding stroke evolution (DEFUSE-2) trial, which was a prospective cohort study where patients planned for endovascular therapy within $12 \mathrm{~h}$ of stroke onset had perfusion MRI imaging prior to the procedure and within $12 \mathrm{~h}$ following the procedure. DEFUSE-2 defined "target mismatch" on baseline imaging as a ratio between the volume of critically hypoperfused tissue and ischemic core of 1.8 or more, with an absolute difference of $15 \mathrm{ml}$ or more, ischemic core volume of $<70 \mathrm{ml}$ and $<100 \mathrm{ml}$ of tissue with a severe delay in bolus arrival $(T \max >10 \mathrm{~s})[19 \bullet]$. Reperfusion was defined as $>50 \%$ reduction in the volume of PWI $T \max >6 \mathrm{~s}$ on early follow-up or TICI2b at the conclusion of the angiographic procedure (in cases where no early MRI was performed). Reperfusion was significantly associated with favorable clinical response (an improvement of 8 or more on the NIHSS between baseline and day 30 or a score of $0-1$ at day 30) in the target mismatch group, but not in the no-target mismatch group. A similar pattern was seen for the secondary outcome of day $90 \mathrm{mRS} \leq 2$. Two interesting post hoc analyses were performed: first, examining the likelihood of favorable clinical response compared to the degree of reperfusion attained with a significant association between the degree of reperfusion and favorable clinical outcome; second, the odds of favorable response in the target mismatch group was compared between patients who had reperfusion treatment starting $\leq 6 \mathrm{~h}$ from onset versus those in whom treatment started $>6 \mathrm{~h}$ from onset. There was no significant difference between the two groups [19•]. Although DEFUSE2 was not a randomized trial of imaging selection, it certainly 
Table 3 Selected ongoing or planned randomized controlled trials using multimodal imaging for patient selection and/or testing interventional revascularization strategies

\begin{tabular}{|c|c|c|c|}
\hline Trial name & $\begin{array}{l}\text { Arterial } \\
\text { criteria }\end{array}$ & Tissue viability criteria & Treatment tested \\
\hline $\begin{array}{l}\text { EXTEND [42] /ECASS-4 (controlled- } \\
\text { trials.com ISRCTN71616222) (EXtending } \\
\text { the Time for Thrombolysis in Emergency } \\
\text { Neurological Deficits/European } \\
\text { Cooperative Acute Stroke Study-4) }\end{array}$ & - & $\begin{array}{l}\text { EXTEND_PWI-DWI or CTP (automated post- } \\
\text { processing). Mismatch ratio }>1.2,>10 \mathrm{ml} \\
\text { absolute mismatch. Ischemic core volume } \\
<70 \mathrm{ml} \\
\text { ECASS-4-PWI-DWI mismatch }\end{array}$ & $\begin{array}{l}\text { IV-rtPA versus placebo } \\
(4.5-9 \mathrm{~h} \text { and wake-up stroke in } \\
\text { EXTEND }[<9 \mathrm{~h} \text { from midpoint } \\
\text { of sleep] })\end{array}$ \\
\hline $\begin{array}{l}\text { EXTEND-IA (EXtending the Time for } \\
\text { Thrombolysis in Emergency Neurological } \\
\text { Deficits with Intra-Arterial Therapy) [67] }\end{array}$ & $\checkmark$ & $\begin{array}{l}\text { CTP (automated post-processing). Criteria as per } \\
\text { EXTEND }\end{array}$ & $\begin{array}{l}\text { IV-rtPA versus IV-rtPA }+ \\
\text { Endovascular (Solitaire) } \\
(<4.5 \mathrm{~h})\end{array}$ \\
\hline $\begin{array}{l}\text { TASTE (Tenecteplase versus Alteplase for } \\
\text { Stroke Thrombolysis Evaluation) } \\
\text { anzctr.org.au ACTRN12613000243718 }\end{array}$ & - & $\begin{array}{l}\text { CTP (automated post-processing)—-stratified } \\
\text { ischemic core by }<25 \mathrm{ml} \text { and } 25-70 \mathrm{ml} \text {. } \\
\text { Mismatch ratio }>1.8 \text {. Absolute } \\
\text { mismatch }>15 \mathrm{~mL} \text {. Tmax }>10 \mathrm{~s}<100 \mathrm{~mL}\end{array}$ & $\begin{array}{l}\text { IV tenecteplase versus IV rtPA } \\
(<4.5 \mathrm{~h})\end{array}$ \\
\hline $\begin{array}{l}\text { DEFUSE-3 (Diffusion and Perfusion Imaging } \\
\text { for Understanding Stroke - 3) - planned }\end{array}$ & $\checkmark$ & $\begin{array}{l}\text { PWI/DWI (automated post-processing - likely } \\
\text { similar criteria to DEFUSE-2) }\end{array}$ & $\begin{array}{l}\text { Endovascular versus standard } \\
\text { management }(<15 \mathrm{~h})\end{array}$ \\
\hline $\begin{array}{l}\text { DIAS-3 (Desmoteplase in Acute Ischemic } \\
\text { Stroke 3) and DIAS-4 [43] }\end{array}$ & $\checkmark$ & $\begin{array}{l}\text { NCCT or MRI excluding extensive early } \\
\text { ischemic change }\end{array}$ & Desmoteplase versus placebo \\
\hline $\begin{array}{l}\text { SWIFT-PRIME (Solitaire }{ }^{\mathrm{TM}} \text { With the } \\
\text { Intention For Thrombectomy as PRIMary } \\
\text { treatment for acute ischemic strokE) } \\
\text { clinicaltrials.gov NCT01657461 }\end{array}$ & $\checkmark$ & PWI/DWI or CTP mismatch & $\begin{array}{l}\text { IV-rtPA versus IV-rtPA }+ \\
\text { Endovascular (Solitaire) } \\
(<4.5 \mathrm{~h})\end{array}$ \\
\hline $\begin{array}{l}\text { REVASCAT (Revascularization with } \\
\text { SOLITAIRE FR }{ }^{\circledR} \text { Device vs. best medical } \\
\text { therapy in the treatment of acute stroke due } \\
\text { to anterior circulation large vessel } \\
\text { occlusion) [66] }\end{array}$ & $\checkmark$ & $\begin{array}{l}\text { Visual assessment of CTP or multimodal MRI } \\
\text { (ASPECTS) in patients }>4.5 \mathrm{~h} \text { from onset or } \\
\text { DWI/NCCT in patients }<4.5 \mathrm{~h} \text { from onset }\end{array}$ & $\begin{array}{l}\text { Endovascular versus standard } \\
\text { management }(<8 \mathrm{~h})\end{array}$ \\
\hline $\begin{array}{l}\text { MR CLEAN (Multicenter Randomized } \\
\text { CLinical trial of Endovascular treatment for } \\
\text { Acute ischemic stroke in the Netherlands) } \\
\text { controlled-trials.com ISRCTN10888758 }\end{array}$ & $\checkmark$ & NCCT or MRI demonstrating no hemorrhage & $\begin{array}{l}\text { Endovascular treatment (IA-rtPA } \\
\text { or urokinase and/or mechanical } \\
\text { thrombectomy) }\end{array}$ \\
\hline $\begin{array}{l}\text { ESCAPE (Endovascular treatment for Small } \\
\text { Core and Anterior circulation Proximal } \\
\text { occlusion with Emphasis on minimizing CT } \\
\text { to recanalization times) clinicaltrials.gov } \\
\text { NCT01778335 }\end{array}$ & $\checkmark$ & $\begin{array}{l}\text { Visual assessment (ASPECTS) of NCCT, CTA } \\
\text { collaterals or CTP }\end{array}$ & $\begin{array}{l}\text { Endovascular versus standard } \\
\text { management }(<12 \mathrm{~h})\end{array}$ \\
\hline $\begin{array}{l}\text { WAKE-UP (Efficacy and Safety of MRI- } \\
\text { based Thrombolysis in Wake-up Stroke) } \\
\text { clinicaltrials.gov NCT01525290 }\end{array}$ & - & $\begin{array}{l}\text { Visual assessment of "DWI-FLAIR mismatch." } \\
\text { Acute ischemic lesion visible on DWI but no } \\
\text { marked parenchymal hyperintensity visible on } \\
\text { FLAIR }\end{array}$ & $\begin{array}{l}\text { IV-rtPA versus placebo for wake- } \\
\text { up strokes }\end{array}$ \\
\hline $\begin{array}{l}\text { DAWN (DWI/PWI and CTP Assessment in } \\
\text { the triage of Wake-up and late presenting } \\
\text { strokes undergoing Neurointervention) }\end{array}$ & $\checkmark$ & Visual assessment of DWI or CTP ASPECTS & $\begin{array}{l}\text { Endovascular versus standard } \\
\text { management for wake-up strokes } \\
\text { or late presentation }(8-24 \mathrm{~h})\end{array}$ \\
\hline
\end{tabular}

CTP computed tomography perfusion; MRI magnetic resonance imaging; ASPECTS alberta stroke program early CT score; DWI diffusion weighted imaging; NCCT non-contrast CT; PWI perfusion weighted imaging; FLAIR fluid attenuated inversion recovery; IV intravenous; IA intra-arterial; $r t P A$ recombinant tissue plasminogen activator

showed that with standardized imaging criteria (particularly exclusion of futile reperfusion cases with the 'malignant profile'), it is possible to reliably identify patients who potentially gain most from effective reperfusion. Interestingly, the post hoc analysis examining the effect of time to reperfusion would also suggest that when robust imaging selection criteria are employed, the time factor might also become less critical, and although this should not be used as a license to be procedurally sluggish, it does highlight the importance of both time and proper patient selection.

Finally, the previous perceived lack of equipoise between intravenous rtPA and intra-arterial interventions is now clearly being challenged. The negative results of these three should motivate all stroke physicians to recruit patients into well-designed randomized controlled trials with appropriate imaging selection, rapid institution of intra-arterial treatment with highly effective devices and 
appropriate follow-up assessment before considering this therapy standard of care. We eagerly await the results of such trials (Table 3).

\section{Thrombolysis in Acute Ischemic Stroke}

Intravenous thrombolysis for acute ischemic stroke was proven to be of benefit in two pivotal randomized controlled trials and is the standard of care in acute ischemic stroke $[32,33]$. Further landmark meta-analyses have both added further strength to this evidence and suggested an important correlation between earlier treatment and the odds of a favorable clinical outcome $[9,34 \cdot]$. The former study suggested a net benefit up to $4.5 \mathrm{~h}$ from onset but an increased mortality thereafter, whereas the latter suggested that while early treatment was the most beneficial, some patients may benefit from treatment up to $6 \mathrm{~h}$ from onset. Although there has been global consensus on the benefit of treatment of ischemic stroke patients within $4.5 \mathrm{~h}$ of onset, in some countries, intravenous rtPA is considered as 'offlabel' in the $3-4.5 \mathrm{~h}$ window and/or in patients above the age of 80 .

This uncertainty of rtPA benefits in patients over the age of 80 and beyond $3 \mathrm{~h}$ led in part to the third international stroke trial (IST-3) [35]. This was a randomized, openlabel, blinded endpoint trial, which aimed to address the question of whether benefit exists in patients in whom there was uncertainty regarding treatment with rtPA, particularly patients over the age of 80 and those who present between 4.5-6 h from onset. The study enrolled a total of 3,035 patients, of whom $53 \%$ were over 80 and $33 \%$ were treated 4.5-6 h after onset. Non-contrast CT was used to exclude hemorrhage and other contraindications. The trial did not show a significant difference in the primary endpoint [adjusted odds ratio of the dichotomized Oxford Handicap Score (OHS) at 6 months], although there was a significant shift in OHS in a pre-specified secondary analysis toward milder degrees of disability in patients treated with rtPA [35]. The OHS is similar to the Rankin scale, being a 6-point scale where 0 is no disability and 5 is complete dependence. Notably, the overall rates of excellent outcome (no or slight disability—a commonly used endpoint in past trials), while is favor of rtPA treatment, were low compared to past trials (24\% for rtPA-treated patients), likely reflecting the relatively 'unselected' nature of the trial. The rate of symptomatic intracranial hemorrhage (SICH) was $7 \%$ in the rtPA group. There was an increased early mortality (first 7 days) in the rtPA group, which was mainly driven by deaths from cerebral causes, although this was counterbalanced by an increased mortality in the control group between 7 days and 6 months [35]. An important follow-up analysis of 18-month outcomes has also been recently published, which demonstrated a significant increase in the odds of OHS 0-2 in the rtPA group (35.0\%) versus the control group $(31.4 \%)$ ( $p=0.024$, number needed to treat $\sim 28$ ) without a difference in survival [36]. This suggests that treatment with rtPA in this group does provide minor benefit without increasing the risk of survival with major disability. This benefit seemed to be driven mainly by patients thrombolyzed in the first $3 \mathrm{~h}$, as demonstrated by another prespecified subgroup analyses of the trial.

IST-3 has contributed much to the recent discussion concerning the optimal design of acute stroke trials and particularly the selection of the optimal statistical methods for assessing the primary outcome. The statistically significant result on shift analysis (a secondary endpoint) has added to a growing trend favoring this analysis method over the traditional dichotomy, and this may become more common in future stroke trials [37].

Similar to the IST-3 trial showing some benefit in patients with borderline indications, a pooled retrospective analysis assessing patients with minor exclusion criteria also showed probable benefit from early thrombolysis [38]. This study included thrombolysis in patients treated with vitamin-K antagonists with an INR $\leq 1.7$ and thrombolysis of patients on chronic antiplatelet monotherapy. However, a recent randomized Dutch trial ARTIS (Antiplatelet therapy in combination with Recombinant t-PA Thrombolysis in Ischemic Stroke) confirmed previous observations that adding aspirin to thrombolysis in aspirin-naïve patients resulted in an unacceptable hemorrhage rate [39].

Attempts to demonstrate benefit of intravenous thrombolysis beyond $4.5 \mathrm{~h}$ have been reminiscent of the intra-arterial trials discussed above and were on the whole generally unfruitful [e.g., the DIAS-II trial (Desmoteplase in Acute Ischemic Stroke-II)] [40]. Despite this, it remains pathophysiologically plausible that some patients should benefit beyond this somewhat arbitrary time point. Again, this heterogeneous treatment response is likely to arise from inherent variability in pathophysiology, in particular a degree of variability in collateral effectiveness between patients. As such, a patient at one end of the spectrum may have very poor collateral circulation and may undergo extensive and irreversible tissue damage very early after onset. Such patients may be at high risk of poor outcome even if treated early. On the other hand, a patient at the other end of the spectrum may have a lesser degree of hypoperfusion and ongoing tissue viability because of excellent collateral status. Such patients may be candidates for treatment beyond the standard time thresholds and may be clinically indistinguishable from the other patients at baseline, and only identifiable based on advanced imaging. The hypothesis of treatment benefit in patients with this positive penumbral profile is supported by evidence from a pooled analysis of the Echo planar Imaging Thrombolytic Evaluation (EPITHET) and 
diffusion and perfusion imaging evaluation for understanding stroke evolution (DEFUSE) studies, which suggests that patients with 'target mismatch' are the ideal candidates for reperfusion [41]. Further prospective trials are currently underway to confirm this hypothesis including extending the time for thrombolysis in emergency neurological deficits EXTEND/ECASS-4 trial (see Table 3) [42] (controlled-trials.com ISRCTN71616222). Similarly, evidence of better treatment response to intravenous thrombolysis in the presence of an intracranial occlusion in DIAS-II led to this arterial imaging criterion in DIAS-3 and DIAS-4 [43] (DIAS-3 results currently being analyzed).

There is also a growing interest in testing other alternative intravenous thrombolytic agents with higher fibrin specificity and potentially greater safety and efficacy than rtPA. A randomized controlled trial of rtPA versus tenecteplase, where standard dose $(0.9 \mathrm{mg} / \mathrm{kg}) \mathrm{rtPA}$ was compared against both $0.1 \mathrm{mg} / \mathrm{kg}$ and $0.25 \mathrm{mg} / \mathrm{kg}$ tenecteplase in patients selected using penumbral imaging up to $6 \mathrm{~h}$ from onset, has recently demonstrated significantly improved reperfusion as well as clinical outcomes with tenecteplase compared with rtPA [31]. A follow-up phase-3 trial to further test this finding is set to begin in early 2014 [Tenecteplase versus Alteplase for Stroke Thrombolysis Evaluation (TASTE), anzctr.org.au ACTRN12613000243718].

These trials share the common concept of selection of patients with a penumbral imaging profile (Fig. 1), although the precise details do vary between the different trials. As described above in the section on intra-arterial trials, we strongly recommend future trials implementing appropriate imaging selection methodologies. Whether it is being used to select patients for intravenous or intra-arterial therapies, we believe there are several critical aspects to a robust imaging selection paradigm. First, we believe a reliable measure of infarct core is essential, and non-contrast CT is not sufficient for this purpose (as it consistently underestimates 'dead brain'). Both MRI (DWI) and CTP $[21,24]$ can fulfill this role. Second, one must determine where the cutoff point lies in terms of infarct core volume. Trials such as EXTEND/ECASS-4 are using a core volume of $<70 \mathrm{ml}$, and the upcoming TASTE trial will stratify randomization based on infarct core $<25$ and $25-70 \mathrm{ml}$. Finally, an assessment of the tissue at risk and collateral status is also crucial, although there is still not consensus on how best to measure this. Dynamic CT angiography holds promise in measuring collateral status [44], but perfusion imaging (MR or CT) can also quantify collateral status [45] and thus has the advantage of avoiding more subjective angiographic grading scales such as American Society of Therapeutic Neuroradiology/Society of Interventional Radiology (SIR) Collateral Flow Grading System (ASITN/SIR) [46].
Fig. 1 Example of advanced imaging in acute stroke. A 76-year-old man presented with right hemiparesis and aphasia (NIHSS 24). Noncontrast CT (a) did not reveal hemorrhage or established ischemic changes. The patient was treated with intravenous rtPA. CTP (b) demonstrated a large area of hypoperfusion (prolonged Tmax), with reduced cerebral blood volume (CBV) and cerebral blood flow $(\mathrm{CBF})$ in the region of the left caudate head and insula. The patient underwent clot retrieval (c) with a final TICI-2b recanalization. DWI at $24 \mathrm{~h}$ demonstrated infarction in the expected distribution predicted by CTP with salvage of most of the hypoperfused hemisphere. NIHSS at $24 \mathrm{~h}$ was 1

\section{Other Interventional Trials for Acute Ischemic Stroke}

The recent randomized SENTIS trial (Safety and Efficacy of NeuroFlo for Treatment of Ischemic Stroke) testing enhancement of collateral (penumbral) flow through diversion of blood from the lower to the upper part of the body by inserting a suboccluding double balloon in the abdominal aorta failed to show a statistically significant benefit [47]. A randomized trial of transcranial LASER therapy for ischemic stroke (NEST-3: NeuroThera Effectiveness and Safety Trial3; clinicaltrials.gov NCT01120301), presumably stimulating mitochondrial activity in lesioned and healthy neurons and glial cells, was halted because of futility. Another semiinvasive trial using stimulation of the spheno-palatine ganglion by a miniature implantable electrode in order to enhance intracranial blood flow is still ongoing in nonthrombolyzed acute stroke patients (ImPACT-1: Implant for Perfusion Augmentation of Cerebral blood flow Trial-1) [48].

Several recent large neuroprotection trials using citicholine [49], cerebrolysin [50] and Chinese Herbal Medicine (MCL601) [51] also showed no benefit. One of the most powerful neuroprotectants in animals, hypothermia, is now being tested in a randomized manner in the ICTUS-2/3 trial (intravenous thrombolysis plus hypothermia for acute treatment of ischemic stroke-2/3) [52]. The preceding pilot study ICTUS-L [53] showed that pneumonia was the most frequent and potentially damaging side effect of cooling. Therefore, the new trial will now monitor for and treat pneumonia aggressively. The randomized Cooling Plus Best Medical Treatment Versus Best Medical Treatment Alone for Acute Ischaemic Stroke (EuroHYP-1; clinicaltrials.gov NCT01833312) trial from the European Stroke Research Network for Hypothermia is now also recruiting and will include both thrombolyzed and non-thrombolyzed patients.

\section{Intracerebral Hemorrhage Trials}

Although ICH is the less common cause of stroke worldwide, numerically it causes more deaths than ischemic stroke [1]. Treatment options for this form of stroke (apart from stroke unit care) are very limited. Research efforts 

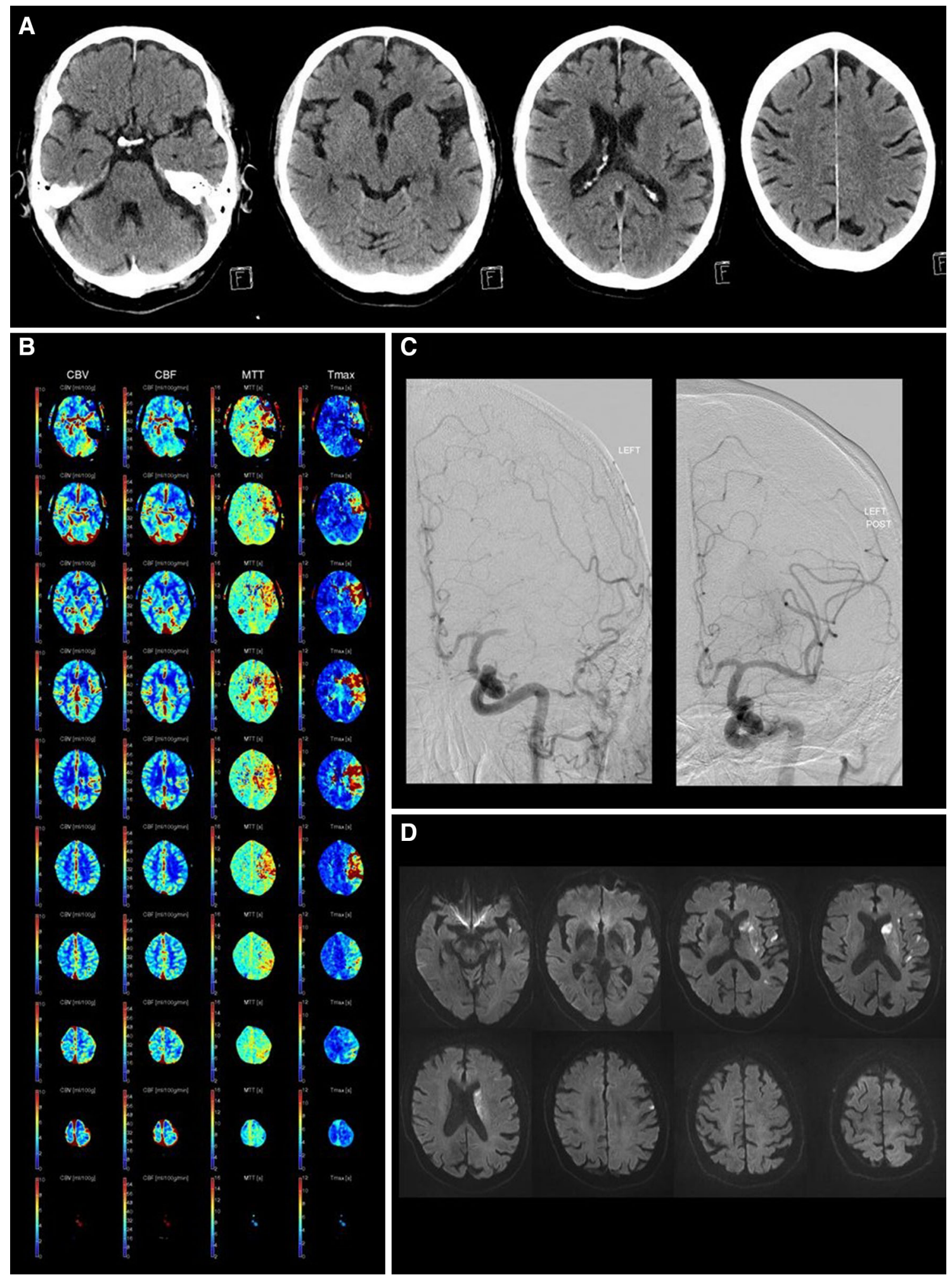

have largely revolved around testing treatments aimed at relief of intracranial pressure effects, evacuation of blood products, hemostatic agents and neuroprotective agents, or a combination of the above.
The second intensive blood pressure reduction in acute cerebral hemorrhage (INTERACT-2) trial was a PROBE design study, which compared the effect of rapid and aggressive blood pressure lowering in hypertensive patients 
after ICH with standard care [54]. Treatment was commenced within $6 \mathrm{~h}$ of stroke onset and continued for 7 days, with a systolic blood pressure target of $140 \mathrm{mmHg}$ in the treatment arm within $1 \mathrm{~h}$ of randomization. The trial recruited 2,794 patients. The primary outcome measure was the proportion of participants with a poor outcome $(\mathrm{mRS} \geq 3)$ at 90 days after randomization. The main secondary outcome was mRS shift (ordinal analysis). Analysis of the primary endpoint revealed $52.0 \%$ of participants in the intensive treatment arm had a poor outcome, compared to $55.6 \%$ in the standard treatment arm [odds ratio (OR) with intensive treatment $0.87 ; 95 \%$ confidence interval $0.75-1.01 ; p=0.06]$. As in IST-3, the ordinal shift analysis indicated a significant favorable shift in the distribution of mRS score with intensive treatment (pooled OR for shift to higher mRS $0.87 ; 95 \% \mathrm{CI}$, $0.77-1.00 ; p=0.04)$. Patients in the treatment arm also had significantly better health-related quality of life scores on the European Quality of Life-5 Dimensions (EQ-5D) scale at 90 days. The rate of death was $11.9 \%$ in the intensive group and $12.0 \%$ in the standard care group, and there was no difference in the incidence of severe hypotension between groups $(0.5 \%$ in the intensive group vs. $0.6 \%$ in the standard care group). Interestingly, there was no significant difference in the effect on hematoma growth between groups on a secondary analysis in a subgroup who had follow-up imaging at $24 \mathrm{~h}$ (approximately one-third of patients). This has led to the suggestion that the borderline statistically significant effect demonstrated in the trial was due to a neuroprotective or edema reduction mechanism of blood pressure lowering rather than attenuation of hematoma growth [54].

The second antihypertensive treatment of the acute cerebral hemorrhage (ATACH-II) trial is currently in progress and seeking to add to the above results [55].

The second International Surgical Trial in Intracerebral Hemorrhage (STICH 2) is the most recent addition to the field of surgical treatment of ICH. This prospective randomized open-label trial recruited patients with spontaneous lobar ICH $\leq 1 \mathrm{~cm}$ from the cortical surface of the brain with a volume of $10-100 \mathrm{ml}$ and within $48 \mathrm{~h}$ of onset, with a best motor score on the Glasgow Coma Scale (GCS) of 5-6 and best eye score of $\geq 2$ [56]. Patients were randomized to early surgery or initial conservative treatment. Early surgery involved evacuation of the hematoma within $12 \mathrm{~h}$, and delayed evacuation was permitted in the initial conservative group. This occurred in 62 patients $(21 \%)$. The primary outcome was a prognosis-based favorable or unfavorable outcome dichotomized from the Extended Glasgow Outcome Scale (GOSE) at 6 months. The prognostic score was derived from an equation including GCS, age and hemorrhage volume.
One hundred twenty-three $(41 \%)$ of 297 patients in the early surgery group had a favorable outcome at 6 months compared with 108 (38\%) of 286 patients in the initial conservative treatment group (OR 0.86, $95 \%$ CI $0.62-1.20 ; p=0.367)$. Mortality at 6 months was $18 \%$ in the early surgery group and $24 \%$ in the initial conservative group $(p=0.095)$ [56]. The authors of the STITCH-II trial also updated their meta-analysis on surgery for ICH in the same paper, which showed a statistically significant reduction in unfavorable outcome with surgery. However, the authors underline the heterogeneity of ICH and the uncertainty about which patients benefit most, suggesting that most benefit of early surgery was derived in patients in the poor prognosis group.

Minimally invasive surgical techniques may hold some promise over more invasive hematoma evacuation, and there have been promising results from trials such as the minimally invasive surgery and rtPA in ICH evacuation (MISTIE) phase II study, which tested a minimally invasive technique involving intraclot infusion of rtPA [57]. Plans are also underway for a phase III trial (clinicaltrials.gov NCT01827046). Aspiration of the hematoma by mini-craniopuncture (with or without using local rtPA to liquefy the clot) shows promising results in Chinese patients in preliminary studies [58, 59], but further randomized trials are necessary.

Concepts of imaging-based selection for ICH trials analogous to ischemic stroke trials have also become more prevalent in recent years. For example, the identification of the contrast extravasation CTA 'spot sign' as a biomarker indicating risk of hematoma expansion $[60,61 \bullet, 62]$ has led to several trials implementing this sign to select patients who are likely to develop hematoma growth and hence be candidates for hemostatic therapy (Fig. 2). Whereas the phase-3 trial of recombinant activated factor VII (rFVII) did not demonstrate benefit [63], the ongoing Spot Sign for Predicting and Treating ICH Growth (STOP-IT) Study (clinicaltrials.gov NCT00810888) and "Spot Sign" Selection of Intracerebral Hemorrhage to Guide Hemostatic Therapy (SPOTLIGHT) Study (clinicaltrials.gov NCT01359202) are aiming to select 'spot sign-positive' patients to investigate the effect of rFVII on hematoma growth in this selected high-risk subgroup. Alternative hemostatic agents are also currently under investigation. Tranexamic acid has recently been demonstrated in a landmark trauma study to reduce all-cause mortality and mortality because of bleeding in trauma patients, particularly when administered early [64]. The Spot Sign and Tranexamic acid on Preventing ICH Growth (STOPAUST) trial aims to test this simple and inexpensive intervention in patients who have been selected using the CTA spot sign [65]. 

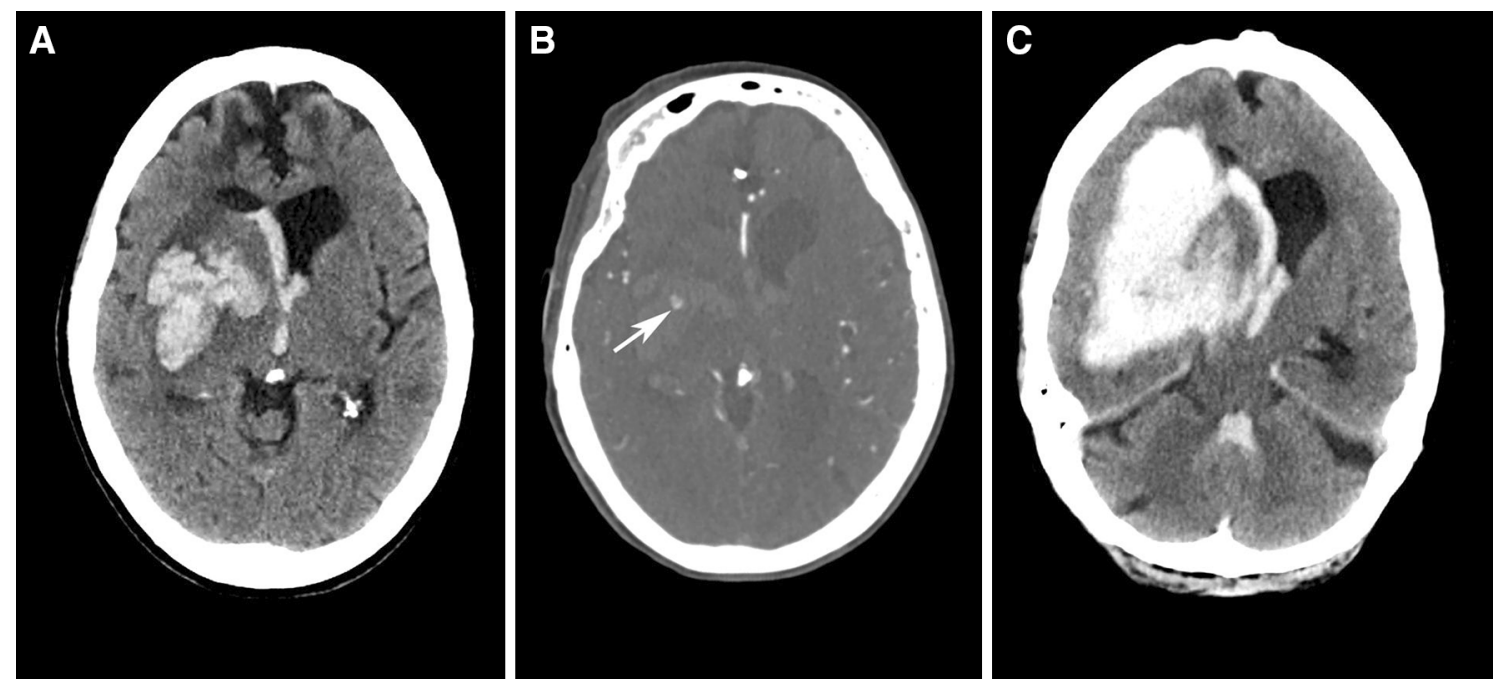

Fig. 2 The CTA spot sign. Right basal ganglia hemorrhage (a) with contrast extravasation ('spot sign') seen on CTA (b). Repeat CT at 2 h (c) demonstrates dramatic increase in hematoma volume

\section{Conclusions}

Multiple highly informative trials in acute stroke management have recently been published in both ischemic stroke and ICH. Several overarching themes are evident in these trials and provide useful insights and directions for future trial design and interpretation. Recruitment into well-designed trials of intra-arterial intervention for ischemic stroke is a foremost priority for the field. These trials will test devices with a proven technical advantage over the first-generation devices and must emphasize the importance of rapid treatment and effective rather than incomplete revascularization.

In ischemic stroke, advanced imaging and penumbral selection may be the key to providing treatment to patients outside the standard time windows, whether this involves treatment with intravenous rtPA, or other more fibrin specific thrombolytics or intra-arterial approaches (or a combination). The penumbral hypothesis may allow more individualized assessment of stroke pathophysiology in each patient in order to determine the potential benefit of recanalization versus the risk of adverse outcomes, as opposed to a strict time-based threshold, which ignores potential individual variation in patients and disease. However, trials such as MR-RESCUE highlight the ongoing controversy around the complexity involved in defining the parameters used to select patients for new therapies with imaging.

The recent interest in early blood pressure lowering and attenuation of hematoma expansion in ICH should be followed by further randomized controlled trials in order to develop new treatments for this devastating condition. Imaging selection in ICH may also allow for an improved understanding of the individual patient's pathophysiology and allow guided treatment selection based on individual patient characteristics.
Other treatment modalities for acute ischemic stroke, including collateral flow enhancement, neuroprotection and hypothermia, have either been shown to be ineffective or are still being tested in randomized trials.

Finally, there has been a recent trend toward the use of ordinal or shift analysis in the analysis of stroke trial results. Several recent trials have been statistically positive using this method but negative on traditional dichotomized methods. Future trial design must focus on an understanding of the nature of the endpoint being studied and on the optimal statistical methods required to demonstrate both a statistically and clinically significant effect.

\section{Compliance with Ethics Guidelines}

Conflict of Interest Nawaf Yassi has nothing to disclose. Patrik Michel's institution receives speaker fees from Boehringer-Ingelheim and Covidien and grant money from the Swiss Cardiology Foundation, Cardiomet CHUV and the Swiss National Science Foundation on his behalf. Dr. Michel's institution also receives payment from Bayer and Pfizer for his board membership and from Pierre-Fabre for his work as a consultant. Mark Parsons has nothing to disclose.

Human and Animal Rights and Informed Consent This article does not contain any studies with animal subjects performed by the authors. All cited human studies in which one of the authors was involved as a co-author received local human research ethics committee approval.

\section{References}

Papers of particular interest, published recently, have been highlighted as:

- Of importance

1. Lozano R, Naghavi M, Foreman K, Lim S, Shibuya K, Aboyans V, et al. Global and regional mortality from 235 causes of death for 20 
age groups in 1990 and 2010: a systematic analysis for the Global Burden of Disease Study 2010. Lancet. 2013;380(9859):2095-128.

2. Murray CJ, Vos T, Lozano R, Naghavi M, Flaxman AD, Michaud C, et al. Disability-adjusted life years (DALYs) for 291 diseases and injuries in 21 regions, 1990-2010: a systematic analysis for the Global Burden of Disease Study 2010. Lancet. 2013;380(9859):2197-223.

3. Broderick JP, Palesch YY, Demchuk AM, Yeatts SD, Khatri P, Hill $\mathrm{MD}$, et al. Endovascular therapy after intravenous t-PA versus t-PA alone for stroke. N Engl J Med. 2013;368(10):893-903.

4. Ciccone A, Valvassori L, Nichelatti M, Sgoifo A, Ponzio M, Sterzi R, et al. Endovascular treatment for acute ischemic stroke. N Engl J Med. 2013;368(10):904-13.

5. Kidwell CS, Jahan R, Gornbein J, Alger JR, Nenov V, Ajani Z, et al. A trial of imaging selection and endovascular treatment for ischemic stroke. N Engl J Med. 2013;368(10):914-23.

6. Nogueira RG, Lutsep HL, Gupta R, Jovin TG, Albers GW, Walker GA, et al. Trevo versus Merci retrievers for thrombectomy revascularisation of large vessel occlusions in acute ischaemic stroke (TREVO 2): a randomised trial. Lancet. 2012;380(9849):1231-40.

7. Saver JL, Jahan R, Levy EI, Jovin TG, Baxter B, Nogueira RG, et al. Solitaire flow restoration device versus the Merci Retriever in patients with acute ischaemic stroke (SWIFT): a randomised, parallel-group, non-inferiority trial. Lancet. 2012;380(9849):1241-9.

8. Saver JL, Fonarow GC, Smith EE, Reeves MJ, Grau-Sepulveda MV, Pan W, et al. Time to treatment with intravenous tissue plasminogen activator and outcome from acute ischemic stroketime to treatment with IV tPA and ischemic stroke. JAMA. 2013;309(23):2480-8.

9. Lees KR, Bluhmki E, Von Kummer R, Brott TG, Toni D, Grotta JC, et al. Time to treatment with intravenous alteplase and outcome in stroke: an updated pooled analysis of ECASS, ATLANTIS, NINDS, and EPITHET trials. Lancet. 2010;375(9727):1695.

10. Khatri P, Yeatts S, Mazighi M, Broderick J, Liebeskind D, Demchuk A et al. Time to angiographic reperfusion is highly associated with good clinical outcome in the interventional management of stroke phase III (IMS III) trial. International Stroke Conference. Hawaii, USA: American Heart Association. 2013.

11. Mazighi M, Chaudhry SA, Ribo M, Khatri P, Skoloudik D, Mokin $\mathrm{M}$, et al. Impact of onset-to-reperfusion time on stroke mortality a collaborative pooled analysis. Circulation. 2013;127(19):1980-5.

12. Fischer U, Arnold M, Nedeltchev K, Brekenfeld C, Ballinari P, Remonda L, et al. NIHSS score and arteriographic findings in acute ischemic stroke. Stroke. 2005;36(10):2121-5.

13. Nakajima M, Kimura K, Ogata T, Takada T, Uchino M, Minematsu K. Relationships between angiographic findings and National Institutes of Health stroke scale score in cases of hyperacute carotid ischemic stroke. Am J Neuroradiol. 2004;25(2):238-41.

14. Yassi N, Parsons MW, Christensen S, Sharma G, Bivard A, Donnan GA, et al. Prediction of poststroke hemorrhagic transformation using computed tomography perfusion. Stroke. 2013;44(11):3039-43.

15. Campbell BC, Christensen S, Parsons MW, Churilov L, Desmond PM, Barber PA, et al. Advanced imaging improves prediction of hemorrhage after stroke thrombolysis. Ann Neurol. 2013;73(4): 510-9.

16. Mlynash M, Lansberg MG, De Silva DA, Lee J, Christensen S, Straka M, et al. Refining the definition of the malignant profile insights from the DEFUSE-EPITHET pooled data set. Stroke. 2011;42(5):1270-5.

17. Davis SM, Donnan GA, Parsons MW, Levi C, Butcher KS, Peeters A, et al. Effects of alteplase beyond $3 \mathrm{~h}$ after stroke in the Echoplanar Imaging Thrombolytic Evaluation Trial (EPITHET): a placebocontrolled randomised trial. Lancet Neurol. 2008;7(4):299-309.

18. Albers GW, Thijs VN, Wechsler L, Kemp S, Schlaug G, Skalabrin E, et al. Magnetic resonance imaging profiles predict clinical response to early reperfusion: the diffusion and perfusion imaging evaluation for understanding stroke evolution (DEFUSE) study. Ann Neurol. 2006;60(5):508-17.
19. • Lansberg MG, Straka M, Kemp S, Mlynash M, Wechsler LR, Jovin TG et al. MRI profile and response to endovascular reperfusion after stroke (DEFUSE 2): a prospective cohort study. Lancet Neurol. 2012;11(10):860-7 This study (DEFUSE-2) demonstrates the possibility of benefit with endovascular therapy with appropriate penumbral imaging selection, particularly the exclusion of patients with the 'malignant profile.'

20. Kidwell CS, Wintermark M, De Silva DA, Schaewe TJ, Jahan R, Starkman S, et al. Multiparametric MRI and CT models of infarct core and favorable penumbral imaging patterns in acute ischemic stroke. Stroke. 2013;44(1):73-9.

21. Bivard A, Spratt N, Levi C, Parsons M. Perfusion computer tomography: imaging and clinical validation in acute ischaemic stroke. Brain. 2011;134(11):3408-16.

22. Parsons M, Pepper E, Bateman G, Wang Y, Levi C. Identification of the penumbra and infarct core on hyperacute noncontrast and perfusion CT. Neurology. 2007;68(10):730-6.

23. Parsons MW, Pepper EM, Chan V, Siddique S, Rajaratnam S, Bateman GA, et al. Perfusion computed tomography: prediction of final infarct extent and stroke outcome. Ann Neurol. 2005;58(5):672-9.

24. Campbell BC, Christensen S, Levi CR, Desmond PM, Donnan GA, Davis SM, et al. Cerebral blood flow is the optimal CT perfusion parameter for assessing infarct core. Stroke. 2011;42(12):3435-40.

25. Parsons MW, Christensen S, McElduff P, Levi CR, Butcher KS, De Silva DA, et al. Pretreatment diffusion-and perfusion-MR lesion volumes have a crucial influence on clinical response to stroke thrombolysis. J Cereb Blood Flow Metab. 2010;30(6):1214-25.

26. Tomsick T, Broderick J, Carrozella J, Khatri P, Hill M, Palesch $\mathrm{Y}$, et al. Revascularization results in the Interventional Management of Stroke II trial. Am J Neuroradiol. 2008;29(3):582-7.

27. Zaidat OO, Yoo AJ, Khatri P, Tomsick TA, von Kummer R, Saver JL, et al. Recommendations on angiographic revascularization grading standards for acute ischemic stroke a consensus statement. Stroke. 2013;44(9):2650-63.

28. Yoo AJ, Chandra RV, Lev MH. Revascularization grading: the devil is in the details. Radiology. 2013;269(1):6-7.

29. Yoo AJ, Simonsen CZ, Prabhakaran S, Chaudhry ZA, Issa MA, Fugate JE, et al. Refining angiographic biomarkers of revascularization improving outcome prediction after intra-arterial therapy. Stroke. 2013;44(9):2509-12.

30. Eilaghi A, Brooks J, d'Esterre C, Zhang L, Swartz RH, Lee T-Y, et al. Reperfusion is a stronger predictor of good clinical outcome than recanalization in ischemic stroke. Radiology. 2013;269(1):240-8.

31. Parsons M, Spratt N, Bivard A, Campbell B, Chung K, Miteff F, et al. A randomized trial of tenecteplase versus alteplase for acute ischemic stroke. N Engl J Med. 2012;366(12):1099-107.

32. The National Institute of Neurological Disorders and Stroke rtPA Stroke Study Group. Tissue plasminogen activator for acute ischemic stroke. N Engl J Med. 1995;333(1):581-1587.

33. Hacke W, Kaste M, Bluhmki E, Brozman M, Dávalos A, Guidetti $\mathrm{D}$, et al. Thrombolysis with alteplase 3 to 4.5 hours after acute ischemic stroke. N Engl J Med. 2008;359(13):1317-29.

34. - Wardlaw JM, Murray V, Berge E, del Zoppo G, Sandercock P, Lindley RL et al. Recombinant tissue plasminogen activator for acute ischaemic stroke: an updated systematic review and metaanalysis. Lancet. 2012;379(9834):2364-72. This updated metaanalysis of randomized-controlled trials of intravenous rtPA versus placebo adds further strength to the evidence behind this therapy, particularly when given early.

35. Sandercock P, Wardlaw J, Lindley R, Dennis M, Cohen G, Murray $\mathrm{G}$, et al. The benefits and harms of intravenous thrombolysis with recombinant tissue plasminogen activator within $6 \mathrm{~h}$ of acute ischaemic stroke [the third international stroke trial (IST-3)]: a randomised controlled trial. Lancet. 2012;379(9834):2352-63.

36. Sandercock P, Wardlaw JM, Dennis M, Cohen G, Murray G, Innes $\mathrm{K}$, et al. Effect of thrombolysis with alteplase within $6 \mathrm{~h}$ of 
acute ischaemic stroke on long-term outcomes [the third International Stroke Trial (IST-3)]: 18-month follow-up of a randomised controlled trial. Lancet Neurol. 2013;12(8):768-76.

37. Bath PM, Lees KR, Schellinger PD, Altman H, Bland M, Hogg $\mathrm{C}$, et al. Statistical analysis of the primary outcome in acute stroke trials. Stroke. 2012;43(4):1171-8.

38. Frank B, Grotta JC, Alexandrov AV, Bluhmki E, Lyden P, Meretoja A, et al. Thrombolysis in stroke despite contraindications or warnings? Stroke. 2013;44(3):727-33.

39. Zinkstok SM, Roos YB. Early administration of aspirin in patients treated with alteplase for acute ischaemic stroke: a randomised controlled trial. Lancet. 2012;380(9843):731-7.

40. Hacke W, Furlan AJ, Al-Rawi Y, Davalos A, Fiebach JB, Gruber $\mathrm{F}$, et al. Intravenous desmoteplase in patients with acute ischaemic stroke selected by MRI perfusion-diffusion weighted imaging or perfusion CT (DIAS-2): a prospective, randomised, double-blind, placebo-controlled study. Lancet Neurol. 2009;8(2):141-50.

41. Lansberg MG, Lee J, Christensen S, Straka M, De Silva DA, Mlynash M, et al. RAPID automated patient selection for reperfusion therapy a pooled analysis of the Echoplanar Imaging Thrombolytic Evaluation Trial (EPITHET) and the Diffusion and Perfusion Imaging Evaluation for Understanding Stroke Evolution (DEFUSE) Study. Stroke. 2011;42(6):1608-14.

42. Ma H, Parsons MW, Christensen S, Campbell BC, Churilov L, Connelly A, et al. A multicentre, randomized, double-blinded, placebo-controlled Phase III study to investigate EXtending the time for Thrombolysis in Emergency Neurological Deficits (EXTEND). Int J Stroke. 2012;7(1):74-80.

43. von Kummer R, Albers GW, Mori E and DIAS Steering Committees. The desmoteplase in acute ischemic stroke (DIAS) clinical trial program. Int J Stroke. 2012;7:589-96.

44. Menon BK, O'Brien B, Bivard A, Spratt NJ, Demchuk AM, Miteff F, et al. Assessment of leptomeningeal collaterals using dynamic CT angiography in patients with acute ischemic stroke. J Cereb Blood Flow Metab. 2012;33(3):365-71.

45. Campbell BC, Christensen S, Tress BM, Churilov L, Desmond PM, Parsons MW, et al. Failure of collateral blood flow is associated with infarct growth in ischemic stroke. J Cereb Blood Flow Metab. 2013;33(8):1168-72.

46. Higashida RT, Furlan AJ, Roberts H, Tomsick T, Connors B, Barr J, et al. Trial design and reporting standards for intraarterial cerebral thrombolysis for acute ischemic stroke. J Vasc Interv Radiol. 2003;14(8):E1-31.

47. Shuaib A, Bornstein NM, Diener H-C, Dillon W, Fisher M, Hammer MD, et al. Partial aortic occlusion for cerebral perfusion augmentation safety and efficacy of neuroflo in acute ischemic stroke trial. Stroke. 2011;42(6):1680-90.

48. Khurana D, Kaul S, Bornstein N. Implant for augmentation of cerebral blood flow trial 1: a pilot study evaluating the safety and effectiveness of the Ischaemic Stroke System for treatment of acute ischaemic stroke. Int J Stroke. 2009;4(6):480-5.

49. Dávalos A, Alvarez-Sabín J, Castillo J, Díez-Tejedor E, Ferro J, Martínez-Vila E, et al. Citicoline in the treatment of acute ischaemic stroke: an international, randomised, multicentre, placebo-controlled study (ICTUS trial). Lancet. 2012;380(9839):349-57.

50. Heiss W-D, Brainin M, Bornstein NM, Tuomilehto J, Hong Z. Cerebrolysin in patients with acute ischemic stroke in asia results of a double-blind, placebo-controlled randomized trial. Stroke. 2012;43(3):630-6.

51. Chen CL, Young SH, Gan HH, Singh R, Lao AY, Baroque AC, et al. Chinese medicine neuroaid efficacy on stroke recovery a double-blind, placebo-controlled, randomized study. Stroke. 2013;44(8):2093-100.

52. Lyden PD, Hemmen TM, Grotta J, Rapp K, Raman R. Endovascular therapeutic hypothermia for acute ischemic stroke: ICTuS 2/3 protocol. Int J Stroke. 2014;9(1):117-25.
53. Hemmen TM, Raman R, Guluma KZ, Meyer BC, Gomes JA, Cruz-Flores $\mathrm{S}$, et al. Intravenous thrombolysis plus hypothermia for acute treatment of ischemic stroke (ICTuS-L) final results. Stroke. 2010;41(10):2265-70.

54. Anderson CS, Heeley E, Huang Y, Wang J, Stapf C, Delcourt C, et al. Rapid blood-pressure lowering in patients with acute intracerebral hemorrhage. N Engl J Med. 2013;368(25):2355-65.

55. Qureshi A, Palesch Y. Antihypertensive Treatment of Acute Cerebral Hemorrhage (ATACH) II: design, methods, and rationale. Neurocrit Care. 2011;15(3):559-76.

56. Mendelow AD, Gregson BA, Rowan EN, Murray GD, Gholkar A, Mitchell PM. Early surgery versus initial conservative treatment in patients with spontaneous supratentorial lobar intracerebral haematomas (STICH II): a randomised trial. Lancet. 2013;382(9890): 397-408.

57. Mould WA, Carhuapoma JR, Muschelli J, Lane K, Morgan TC, McBee NA, et al. Minimally invasive surgery plus recombinant tissue-type plasminogen activator for intracerebral hemorrhage evacuation decreases perihematomal edema. Stroke. 2013;44(3):627-34.

58. Wang WZ, Jiang B, Liu HM, Li D, Lu CZ, Zhao YD, et al. Minimally invasive craniopuncture therapy vs. conservative treatment for spontaneous intracerebral hemorrhage: results from a randomized clinical trial in China. Int J Stroke. 2009;4(1):11-6.

59. Zhou H, Zhang Y, Liu L, Huang Y, Tang Y, Su J, et al. Minimally invasive stereotactic puncture and thrombolysis therapy improves long-term outcome after acute intracerebral hemorrhage. J Neurol. 2011;258(4):661-9.

60. Goldstein JN, Fazen L, Snider R, Schwab K, Greenberg SM, Smith EE, et al. Contrast extravasation on CT angiography predicts hematoma expansion in intracerebral hemorrhage. Neurology. 2007;68(12):889-94.

61. • Wada R, Aviv RI, Fox AJ, Sahlas DJ, Gladstone DJ, Tomlinson $\mathrm{G}$ et al. CT angiography "spot sign" predicts hematoma expansion in acute intracerebral hemorrhage. Stroke. 2007;38(4):1257-62. This article describes the CTA "spot sign," an important potential imaging selection tool in ICH. This is currently being utilized in several trials of hemostatic therapy in $\mathrm{ICH}$.

62. Aviv R, Gladstone D, Goldstein J, Flaherty M, Broderick J, Demchuk A. Contrast extravasation predicts hematoma growth: where to now? Am J Neuroradiol. 2008;29(9):e80.

63. Mayer SA, Brun NC, Begtrup K, Broderick J, Davis S, Diringer MN, et al. Efficacy and safety of recombinant activated factor VII for acute intracerebral hemorrhage. N Engl J Med. 2008;358(20):2127-37.

64. Shakur H, Roberts I, Bautista R, Caballero J, Coats T, Dewan Y, et al. Effects of tranexamic acid on death, vascular occlusive events, and blood transfusion in trauma patients with significant haemorrhage (CRASH-2): a randomised, placebo-controlled trial. Lancet. 2010;376(9734):23-32.

65. Meretoja A, Churilov L, Campbell BC, Aviv RI, Yassi N, Barras $\mathrm{C}$, et al. The Spot sign and Tranexamic acid On Preventing ICH growth - AUStralasia Trial (STOP-AUST): Protocol of a phase II randomized, placebo-controlled, double-blind, multicenter trial. Int J Stroke. 2013; doi:10.1111/ijs.12132.

66. Molina CA, Chamorro A, Rovira À, Miquel A, Serena J, Roman LS, et al. REVASCAT: a randomized trial of revascularization with SOLITAIRE FR ${ }^{\circledR}$ device vs. best medical therapy in the treatment of acute stroke due to anterior circulation large vessel occlusion presenting within eight-hours of symptom onset. Int $\mathbf{J}$ Stroke. 2013;. doi:10.1111/ijs.12157.

67. Campbell BC, Mitchell PJ, Yan B, Parsons MW, Christensen S, Churilov L, et al. A multicenter, randomized, controlled study to investigate EXtending the time for Thrombolysis in Emergency Neurological Deficits with Intra-Arterial therapy (EXTEND-IA). Int J Stroke. 2013;9(1):126-32. 